\title{
European species and habitat monitoring: where are we now?
}

\author{
Dirk S. Schmeller
}

Published online: 31 October 2008

(C) Springer Science+Business Media B.V. 2008

\begin{abstract}
Biodiversity now is considered a highly valuable material, providing manifold services of high importance for the well-being of humankind. However, biodiversity globally is rapidly diminishing and, despite efforts to halt the loss of biodiversity, positive effects are hardly visible. Biodiversity monitoring, the close observation of our natural environment, is imperative to determine the state and trend of organism populations and their habitats. Therefore, it has become a centrepiece of nature conservation across the globe. However, monitoring activities are not centrally coordinated, differ vastly in their monitoring targets, sampling designs, and human resource needs. This special issue on biodiversity and monitoring presents an overview of the current state of biodiversity monitoring in Europe, gives suggestions for the integration of monitoring data to improve the geographical and taxonomic coverage, deals with general methodological aspects of monitoring biodiversity across different geographic scales, the involvement of the public in monitoring activities, and provides some monitoring case studies. The special issue is aimed to provide recommendations and suggestions for more standardized monitoring approaches, and is mainly based on the findings of the EU-project EuMon.
\end{abstract}

Keywords Species conservation $\cdot$ Citizen science $\cdot$ Conservation priorities $\cdot$ National responsibility $\cdot$ Europe $\cdot$ International importance $\cdot$ Distribution range

\section{Introduction}

Biodiversity has its own intrinsic value, but is also increasingly recognized for its 'goods and services' to humankind. In response to global, European, regional, or national commitments,

\footnotetext{
D. S. Schmeller $(\bowtie)$

Department of Conservation Biology, UFZ-Helmholtz Centre for Environmental Research, Permoserstr. 15, 04318 Leipzig, Germany

e-mail: ds@die-schmellers.de
}

D. S. Schmeller

Station d'Ecologie Expérimentale du CNRS à Moulis, 09200 Saint Girons, France 
countries are implementing conservation plans to halt the further degradation of biodiversity (Convention on Biological Diversity, http://www.biodiv.org; EU; Council Directive 79/409/EEC of 2 April 1979 on the conservation of wild birds - the Birds Directive; Council Directive 92/43/EEC of 21 May 1992 - the Habitats Directive). Though there is a strong political commitment to reduce or even halt the loss of biodiversity by 2010 , and current research on the development of indicators of biodiversity and methods to determine the state of and trends in biodiversity, there is as yet no common framework that translates monitoring efforts into policy (Balmford et al. 2005). However, policymakers need to know if the decisions they take and the instruments that are developed to implement the decisions to protect and use biodiversity in a sustainable manner are effective. Managers need to know to what extent they are meeting the goals of EU Directives and biodiversity conservation strategies. Furthermore, policy decisions and management actions should be effective, coherent, and consistent. The public should also have access to such assessments and should be involved more in conservation issues.

Recommendations on how to monitor biodiversity are numerous (e.g. Balmford et al. 2003; Mace 2005; Pereira and Cooper 2006), but are seemingly widely left unconsidered, given the results of the EuMon survey on European monitoring systems (Henry et al., this issue; Lengyel et al., this issue; but see also Marsh and Trenham 2008). The basic methodological challenges are still the same: How can we get reliable observations from nature to draw conclusions as to how species and ecosystems are changing through time and space? Reasons for low reliability of observations include biased, non-representative sampling designs, and/or inadequate sampling effort, resulting in low statistical power to detect changes (e.g., Taylor and Gerrodette 1993). To overcome such shortcomings, which may lead to poor quality monitoring (Legg and Nagy 2006; Nichols and Williams 2006), a long list of recommendations has been put forward, including unbiased selection of sampling units for monitoring, using controlled experimental approaches, and ensuring adequate spatial and temporal replication by a sufficient sampling effort. Despite extensive knowledge on sound approaches for the monitoring of biodiversity, much of the current monitoring efforts are sub-optimal in data collection and/or analysis, and do not yield as robust results from their efforts as theoretically possible. The latter is not only true for European monitoring practices, but also for species monitoring in North America (Marsh and Trenham 2008). There is clearly a strong need to make the accumulated body of knowledge on biodiversity monitoring more easily available to scientists, monitoring programme coordinators, and various users of monitoring results. To reach a broader public, the results of EuMon, in large parts the subject of this Special Issue (but see also Schmeller et al. 2008; in press), were integrated in the online tool BioMAT (EuMon 2008) to assist in the design of new monitoring schemes, data analysis, and integration across temporal and geographical scales.

\section{Organisation and contents}

The contributions to this Special Issue on biodiversity and monitoring are divided into five sections: (1) the current species and habitat monitoring situation in Europe; (2) methodological issues in ground observation and remote sensing, (3) volunteer involvement in biodiversity monitoring; (4) monitoring case studies; and (5) monitoring priorities as derived from national responsibilities.

The EuMon survey of European monitoring practices, summarized in the online database DaEuMon (EuMon 2008), allowed the drawing of a detailed picture of monitoring 
practices in European species and habitat monitoring (Henry et al., this issue; Kull et al., this issue; Lengyel et al., this issue; Schmeller et al. in press). The results show that biodiversity monitoring is not following a standardized approach in Europe, making it difficult to assess the state and trend of biodiversity across geographical and temporal scales from collected raw data. Policymakers, however, need to know now, if environmental policies, natural resource use and biodiversity management have an effect on the species and habitats. Hence, we need to assess changes in biodiversity now, combining output available from ongoing monitoring initiatives as the only option. Data integration of biodiversity information across schemes is still very poorly developed. Benefits, methods and limits are addressed in two contributions by Henry et al. (this issue) and Lengyel et al. (this issue). Habitat monitoring, which is still on the verge of large scale development, could profit from the suggestions of standardization and data integration.

The second section of the special issue addresses problems in ground observation and remote sensing, and provides some recommendations for methodological improvements. One major problem in species monitoring is the heterogeneity in species and individual detectability. However, the most recently developed techniques to include detection probability in the analysis of count data are limited (Bas et al., this issue). Further, it is of importance for biodiversity assessment and management implementation to know the parameters of population growth and regulation. In EU-countries, the detection of population trends is even a legal obligation due to the demands of the Nature Directives (i.e. Evans 2005). Yet, inherent process and measurement errors weaken the ability to estimate population growth and dynamics from population time-series. Solutions to this problem are given in Hovestadt and Nowicki (this issue). For remote sensing, high resolution satellite images have been hailed as a useful source of data for biodiversity assessment and monitoring. However, the availability of remotely sensed data is biased toward temperate areas. The tropics, with much higher levels of biodiversity, challenge the application of hyperspatial and hyperspectral remote sensing. Nagendra and Rocchini (this issue) examine issues related to hyperspatial and hyperspectral remotely sensed imagery and pinpoint application limitations due to pixel resolution.

For collecting biodiversity data on a large scale, covering a large amount of different species groups, with sufficient precision to detect changes over time and space, a large amount of human resources is needed. Employing only professionals for these tasks is hardly possible due to the usually limited budget that countries allocate to nature conservation. Most large scale monitoring schemes (e.g. butterfly monitoring, van Swaay et al., this issue) are maintained by a small group of professionals coordinating large groups of volunteer naturalists, giving a unique opportunity to thousands of citizens to be actively involved in biodiversity monitoring, environmental science, and conservation. To keep volunteers motivated, and to recruit and attract even more is not such an easy task as it looks on first sight (Bell et al., this issue; Podjed et al., this issue). Major difficulties can arise from changes in the structure and general accessibility of monitoring organisations. Further, professionalism may have a negative impact on voluntarism and may result in the reduction of the initial altruistic sentiments among members and hence decrease their willingness to participate (Podjed et al., this issue). Further, volunteers place a high degree of significance on their social experience within monitoring networks (Bell et al., this issue). Hence, successful creation and management of such networks requires that similar levels of attention are paid to social aspects of the organisation as well as to the generation and management of data. Besides organisational and social difficulties, volunteer involvement in habitat monitoring is limited due to the need of profound species identification skills. A solution to the problem could be the use of morphotypes, which would allow less experienced naturalists 
to carry out indicative surveys. Difficulties in this approach, such as the sensitivity of morphotypes to differences among habitats, and variation in morphotype identification, are discussed by Abadie et al. (this issue). The example on butterfly monitoring in Europe (Van Swaay et al., this issue) might provide a good blueprint for the establishment of monitoring networks for groups other than the-so intensively monitored-birds (Gregory et al. 2005; European Environment Agency (EEA) 2007). Butterfly monitoring schemes are aimed at assessing regional and national trends in butterfly abundance per species, and have created a network between regional and national coordinators in different countries.

The involvement of local people (e.g. urban citizens) is also a rich source of information. Local ecological knowledge (LEK) of non-scientists, but who are people who earn their living from natural environments, is an as yet little explored source of insights into changes in biodiversity and also ecological processes. Kendall and McLachlan (this issue) review the literature to see the extent to which LEK has entered ecological research during the last 25 years.

The case studies exemplify the methodological aspects of a mark-recapture approach for a survey of an endangered, native crustacean, the white-clawed crayfish (Austropotamobius pallipes complex, Nowicki et al., this issue), illustrate the usage of old distribution records from earlier collected data to determine more recent large-scale changes in regional floras to evaluate conservation targets and redefine future management targets (Sammul et al., this issue), and show negative effects of forest management techniques on the abundance of an arboreal rodent, the Common Dormouse (Muscardinus avellanarius) (Juškaitis this issue). A study on Greek habitats (Mazaris et al., this issue) illustrates that despite the proportionally higher numbers of restricted species, widespread species make a greater contribution to overall richness patterns. Hence, their findings highlight the importance of widespread species as biodiversity indicators. Finally, a study from Namibia details methodological aspects and problems of camera trapping for monitoring rare species (Stein et al., this issue). They conclude that camera-trapping efforts can be incorporated into longterm monitoring programs.

Lastly, three contributions deal with gaps between management and monitoring priorities and actual monitoring practices and needs. Buckley et al. (this issue) describe the situation in Australia, one of the most important biodiversity hotspots. The authors track changes in monitoring and management priorities and actual monitoring practices over temporal and geographical scales. They show only a weak match between reported management priorities and actual monitoring programmes. Further, only rarely was the effectiveness of management responses found to be monitored. The experience of EuMon and recent literature (Donald et al. 2007) show a similar situation in Europe. To solve that problem, Schmeller et al. (this issue) present newly developed methods for the determination of national responsibilities and conservation priorities for the conservation of species. In combination, the methods allow the allocation of the limited financial resources available for nature conservation in the most sensible way, and would allow sharing monitoring duties, improving knowledge on biodiversity, and filling information gaps in many species groups. For that, the method sets recommendations for necessary monitoring actions. These actions range from the close monitoring of rare species, to the setting up of new monitoring programmes, if the knowledge base for a certain group of species is low. Further, the method recommends the redirection of monitoring resources, if the organization is located in a country with just basic conservation responsibilities for a certain species.

The content of this Special Issue on biodiversity and monitoring gives general guidelines and ideas for improvement of current monitoring practices and complements the vast body of literature on the subject. Further, the EuMon database (EuMon 2008) contains a 
large set of contact details of monitoring coordinators across Europe. The information included could be used to create monitoring networks across countries, improve the exchange of information between monitoring coordinators, and in more general ways provide a source of information for governmental bodies as to what species and habitat monitoring programmes are currently running in their countries. The latter is important in regard to the obligatory reporting on the state of and trends in biodiversity following from the European Nature Directives (Evans 2005).

\section{References}

Abadie $\mathrm{J}-\mathrm{C}$, Andrade $\mathrm{C}$, Machon $\mathrm{N}$ et al (this issue) On the use of parataxonomy in biodiversity monitoring: a case study on wild flora. Biodivers Conserv. doi:10.1007/s10531-008-9354-z

Balmford A, Green R, Jenkins M (2003) Measuring the changing state of nature. Trends Ecol Evol 18:326-330

Balmford A, Crane P, Dobson A et al (2005) The 2010 challenge: data availability, information needs and extraterrestrial insights. Philos Trans R Soc B-Biol Sci 360(1454):221-228

Bas Y, Devictor V, Moussus J-P et al (this issue) Accounting for weather and time-of-day parameters when analysing count data from monitoring programs. Biodivers Conserv. doi:10.1007/s10531-008-9420-6

Bell S, Marzano M, Cent J et al (this issue) What counts? Volunteers and their organisations in the recording and monitoring of biodiversity. Biodivers Conserv. doi:10.1007/s10531-008-9357-9

Buckley R, Robinson J, Carmody J et al (this issue) Monitoring for management of conservation and recreation in Australian protected areas. Biodivers Conserv. doi:10.1007/s10531-008-9448-7

Donald PF, Sanderson FJ, Burfield IJ et al (2007) International conservation policy delivers benefits for birds in Europe. Science 317(5839):810-813

EuMon 2008: EU-wide monitoring methods and systems of surveillance for species and habitats of community interest, http://eumon.ckff.si/

European Environment Agency (EEA) 2007. Halting the loss of biodiversity by 2010: proposal for a first set of indicators to monitor progress in Europe. Office for Official Publications of the European Communities. http://reports.eea.europa.eu. Cited 6 Dec 2007

Evans D (2005) Natura 2000: completing the EU's network of sites to conserve flora and fauna. PlantTalk 39:22-27

Gregory RD, van Strien A, Vorisek P, Gmelig Meyling AW, Noble DG, Foppen RPB, Gibbons DW (2005) Developing indicators for European birds. Philos Trans R Soc Lond Ser B Biol Sci 360:269-288

Henry P-Y, Lengyel S, Nowicki P et al (this issue) Integrating ongoing biodiversity monitoring: potential benefits and methods. Biodivers Conserv. doi:10.1007/s10531-008-9417-1

Hovestadt T, Nowicki P (this issue) Process and measurement errors of population size: Their mutual effects on precision and bias of estimates for demographic parameters. Biodivers Conserv. doi:10.1007/ s10531-008-9426-0

Juskaitis R (this issue) Long-term common dormouse monitoring: effects of forest management on abundance. Biodivers Conserv. doi:10.1007/s10531-008-9470-9

Kendall Brook R, McLachlan SM (this issue) Trends and prospects for local knowledge in ecological and conservation research and monitoring. Biodivers Conserv. doi:10.1007/s10531-008-9445-x

Kull T, Sammul M, Kull K et al (this issue) Necessity and reality of monitoring threatened European vascular plants. Biodivers Conserv. doi:10.1007/s10531-008-9432-2

Legg CJ, Nagy L (2006) Why most conservation monitoring is, but need not be, a waste of time. J Environ Manag 78(2):194-199

Lengyel S, Déri E, Varga Z et al (this issue) Habitat monitoring in Europe: a description of current practices. Biodivers and Conserv. doi:10.1007/s10531-008-9395-3

Lengyel S, Kobler A, Kutnar L et al (this issue) A review and a framework for the integration of biodiversity monitoring at the habitat level. Biodivers Conserv. doi:10.1007/s10531-008-9359-7

Mace GM (2005) Biodiversity—an index of intactness. Nature 434(7029):32-33

Marsh DM, Trenham PC (2008) Current trends in plant and animal population monitoring. Conserv Biol 22(3):647-655

Nichols JD, Williams BK (2006) Monitoring for conservation. Trends Ecol Evol 21:668-673

Nowicki P, Tirelli T, Sartor SM et al (this issue) Monitoring crayfish using a mark-recapture method: potentials, recommendations, and limitations. Biodiver and Conserv. doi:10.1007/s10531-008-9425-1

Pereira HM, Cooper HD (2006) Towards the global monitoring of biodiversity change. Trends in Ecol Evol 21(3):123-129 
Podjed D, Muršič R (this issue) Dialectical relations between professionals and volunteers in a biodiversity monitoring organisation. Biodivers Conserv. doi:10.1007/s10531-008-9443-Z

Nagendra H, Rocchini D (this issue) High resolution satellite imagery for tropical biodiversity studies: the devil is in the detail. Biodivers Conserv. doi:10.1007/s10531-008-9479-0

Sammul M, Kull T, Lanno K et al (this issue) Habitat preferences and distribution characteristics are indicative of species long-term persistence in the Estonian flora. Biodivers Conserv. doi:10.1007/s10531-008-9393-5

Schmeller DS, Gruber B, Budrys E et al (2008) National responsibilities in European species conservation: a methodological review. Conserv Biol 22(3):593-601

Schmeller DS, Henry P-Y, Julliard R et al (in press) Advantages of volunteer-based biodiversity monitoring in Europe. Conserv Biol

Stein A, Fuller TK, Marker LL (this issue) Opportunistic use of camera traps to assess habitat-specific mammal and bird diversity in northcentral Namibia. Biodivers Conserv. doi:10.1007/s10531-008-9442-0

Taylor BL, Gerrodette T (1993) The uses of statistical power in conservation biology: the vaquita and northern spotted owl. Conserv Biol 7(3):489-500

Van Swaay CAM, Nowicki P, Settele J et al (this issue) Butterfly Monitoring in Europe-methods, applications and perspectives. Biodivers Conserv. doi:10.1007/s10531-008-9491-4 